\title{
Evaluation about Detection of Defects in the Nuclear Piping Loop System Using Lock-in Infrared Thermography
}

\author{
by S. C. KIM *, H. C. JUNG ** and K. S. KIM *** \\ * Department of Mechanical System Engineering, Chosun University, Gwangju, Korea, bluerune@nate.com \\ ** Department of Mechanical System Engineering, Chosun University, Gwangju, Korea, hyunchul.jung@ \\ chosun.ac.kr \\ *** Department of Mechanical System Engineering, Chosun University, Gwangju, Korea, gsckim@chosun.ac.kr
}

\begin{abstract}
Using lock-in IR thermography, detection conditions of defect in pipeline for nuclear power plant has been studied according to incidence angle. Defects are manufactured by changing length of wall thinning, angle in circumferential direction, and amount of wall thinning. Corresponding pipe with defect is used to build loop pipeline system for nuclear power plant, and lock-in IR thermography for cold defect condition is applied to detect heating defect. IR thermography camera and cooling unit is used, and distance between cooling device and target loop system is set to $2 \mathrm{~m}$ away. For the analysis on experimental results, cooling temperature distribution and phase data are gathered to measure the length of defect.
\end{abstract}

\section{Introduction}

To prevent wall thinning and damage in pipeline for nuclear power plant, non-destructive test before and during operation is usually implemented. In addition, to shorten the cycle of testing or increase the quality of inspection, test time and cost will be increased significantly. To compensate these shortcomings, many non-destructive testing methods have been developed, and to increase the chance of catching wall thinning and possibility of damage using nondestructive testing is to shorten the cycle of corresponding test. This would be the most important factor to ensure quality. As the number of nuclear power plant operations increases and therefore the power plants are rapidly aging, the use of non-destructive tests, which can be performed relatively safe and quick, is also increasing. In addition, nuclear power plant piping used for a long period of time is subject to various types of deterioration such as fatigue, corrosion, and wallthinning defect. Among them, the wall-thinning defect caused by low accelerated corrosion is one of major causes that degrade the health of nuclear power plant piping [1,2]. The wall-thinning defect progresses without any sign of damage and commonly occurs in the base metal as well as in the weld, making it difficult to detect the defect through the conventional operation test. For this reason, nuclear power plants operate a separate wall-thinning defect management program and accordingly carry out wall-thickness test for parts with high possibility of wall-thinning defects [3, 4]. For inspection of the pipe thickness, ultrasonic test is most commonly used but it takes a lot of time since it has to measure the thickness at all lattice points. For pipes with small diameters, radiographic inspection is used but it lacks quantization for defects, has a risk of exposing the inspector to radiation and therefore has a limitation in field application [5, 6].Among non-contact, non-destructive testing techniques that can detect several wall-thinning defects quickly and simply, Infrared Thermography (IRT) has been studied for application [7, 8]. But IR thermography method is limited to image processing technique, and further improvement, such as micro defect or exact location determination, is needed. To overcome the limitation of thermography, which is usually used to detect temperature change and its post-processing, lock-in mode thermography is developed to obtain precise image. Generally according to the types of defects, light, ultrasound, vibration, eddy current, etc., which can be easily controlled by harmonic function, are used for excitation source according to defect type. In this study, lock-in IR thermography is used to determine test condition for defect identification.

\section{Equipment and Objects}

\subsection{Camera}

The camera used for this study is as shown in Fig.1, and its specifications are listed in Table 1. Infrared thermography is a technique that calculates phase and amplitude through digital signal processing with a high resolution $\left(0.02^{\circ} \mathrm{C}\right)$ in order to measure minute changes in temperature in a mechanical structure. In this study, preceding experiments were performed in two conditions: First one was to assume that the nuclear power plant was shut down due to regular inspection and the other one was to assume that it was operating normally. In these two conditions, the state of pipes at normal temperature was inspected outside through heat flow of silicon oil inside the pipes. However, in this study, the insulation was not taken into consideration. 


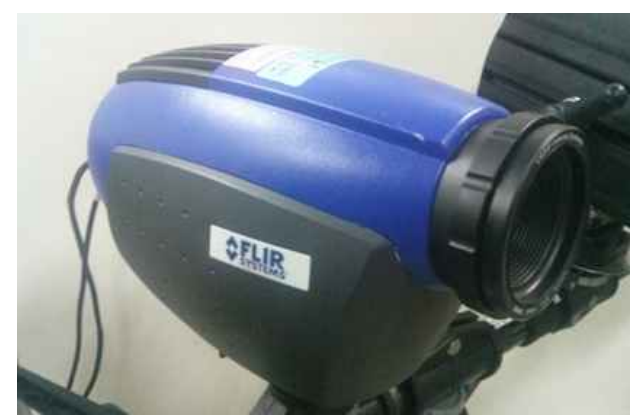

Figure 1. Infrared Camera

Table 1. Specification of Infrared Camera

\begin{tabular}{|c|c|}
\hline \multicolumn{2}{|c|}{ Infrared Camera (FLIR,. SC 5200) } \\
\hline Detector Materials & InSb (Indium Antimonide) \\
\hline Cooling method & Stirling Cooler \\
\hline $\begin{array}{l}\text { Spectral Response } \\
\text { (um) }\end{array}$ & $3.7 \sim 5.0$ \\
\hline Number of Pixels & $320 \times 256$ \\
\hline Pitch (um) & $30 \times 30$ \\
\hline NETD & $25 \mathrm{mK} @ 25^{\circ} \mathrm{C}$ \\
\hline Measure range $\left({ }^{\circ} \mathrm{C}\right)$ & $-15 \sim 2000$ \\
\hline Frame rate $(\mathrm{Hz})$ & $5 \sim 400$ \\
\hline
\end{tabular}

\subsection{Cooling device(Fan)}

Fan cooler with better directionality and high speed is used for the study. Wind blower can cool the corresponding specimen via forced convection using the difference between fan inlet and outlet. Also, better directionality can ensure cooling in $2 \sim 3 \mathrm{~m}$ away. Fan cooler features aluminum die casting blade, and weight is reduced to $11 \mathrm{~kg}$. Maximum wind speed is $16.5 \mathrm{~m} / \mathrm{sec}$, and blade length is $270 \mathrm{~mm}$ to ensure uniform cooling on pipe specimen. Fig. 2 shows the picture of fan cooler with high speed blower. According to the distance between pipe and 2 cooling units and the one between pipe and IR thermography camera, the analysis results are reviewed. $70 \%$ of rated power is applied on halogen lamp, and cooling lock-in IRT is used for image collection. Cooling cycle is set to $0.1 \mathrm{~Hz}$.

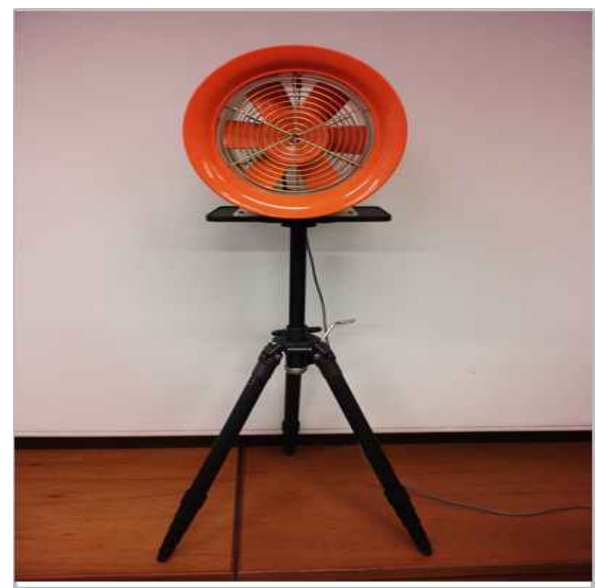

Figure 2. Cooling device 


\subsection{1/qirt.2016.058}

\subsection{Heat Flow System}

For this study, a loop system as shown in Fig. 3 was made using 2.5-inch pipes of ASTM A106 Gr.B carbon steel, and its specifications are shown in Table 2. In order to simulate a high-temperature pipe system of a normally operating nuclear power plant, the temperature inside the pipes was maintained at 250 using silicon oil. Distance between the cooling device and the pipe was set to $1.5 \mathrm{~m}$. Thermal properties of the ASTM A106 Gr.B carbon steel pipe used for this study are shown in Table 2.

Table 2. Specification of piping loop system

\begin{tabular}{|c|c|}
\hline \multicolumn{2}{|c|}{ Piping Loop system } \\
\hline Pipe type & 2.5 inch Pipe \\
\hline Operating temperature & $\mathrm{T}>250^{\circ} \mathrm{C}$ \\
\hline Pressure & atmospheric pressure \\
\hline Inside fluid & silicone oil \\
\hline Pump of capacity & $40 \mathrm{l} / \mathrm{min}$ \\
\hline Heater of capacity & $20 \mathrm{~kW}$ \\
\hline
\end{tabular}

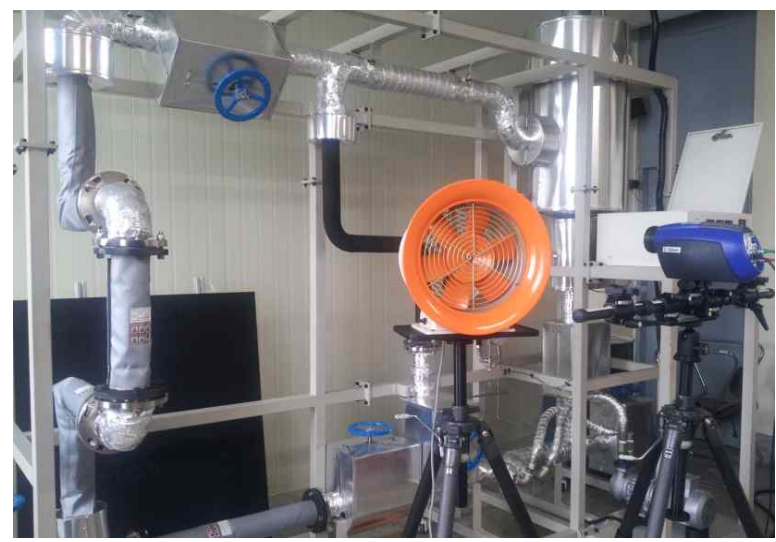

Figure 3. Loop system and infrared thermography

\subsection{Wall-thinned Pipe Specimen}

In order to perform this experiment, the pipes made with the materials actually used in a nuclear power plant were used and defects with the following conditions were processed inside the pipes. The 2.5-inch pipe with the thickness (t) of $7.5 \mathrm{~mm}$, the length $(\mathrm{L})$ of $350 \mathrm{~m}$ and $700 \mathrm{~mm}$, and the outer diameter (Do) of $113 \mathrm{~mm}$ was processed to have defects with $\mathrm{L} / \mathrm{Do}=0.5(56.5 \mathrm{~mm})$ for straight pipes and ones with $\mathrm{L} / \mathrm{Do}=0.25(28.5 \mathrm{~mm})$ for complex pipes, as shown in Fig.4. In addition, the part where the transverse center line of the defect in the circumferential direction was horizontal to the infrared camera was changed to $0^{\circ}$ as shown in Fig.4 (b), and the defect depth was regularly changed according to the pipe thickness, as shown in Table 4 below. 


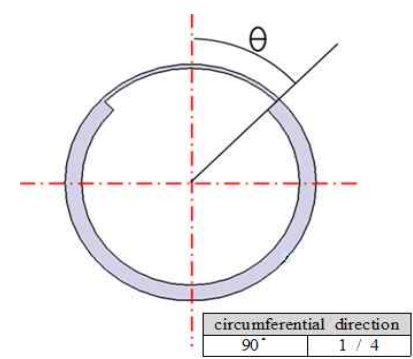

(a) pipe according to circumferential direction

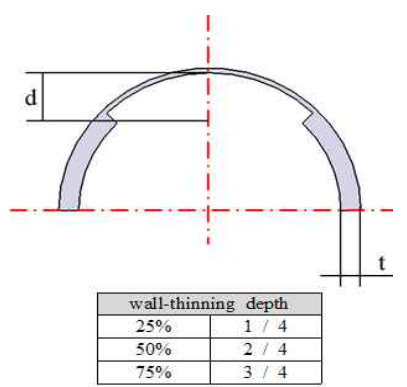

(b) pipe according to wall-thinning depth

Figure 4. Dimensions of defects in pipe

Table 3. Dimensions of the specimen and wall-thinning defect

\begin{tabular}{|c|c|c|c|c|}
\hline Specimen & Pipe Type & Thinning Depth $(d / t)$ & $\begin{array}{c}\text { Thinning } \\
\text { Length }\left(L / D_{0}\right)\end{array}$ & Thinning Angle $(\theta / \pi)$ \\
\hline \multirow[t]{3}{*}{$700 \mathrm{~mm}$} & \multicolumn{3}{|c|}{$\sqrt{6}$} & $\sqrt{8}$ \\
\hline & straight(a) & $0.75,0.25,0.5,0.25$ & 0.25 & 0.25 \\
\hline & straight(b) & 0.5 & 0.5 & 0.25 \\
\hline \multirow[t]{2}{*}{$350 \mathrm{~mm}$} & \multicolumn{3}{|c|}{$\ell / D$} & \\
\hline & straight & $\begin{array}{c}0.75,0.5,0.75,0.5 \\
0.75\end{array}$ & 0.25 & 0.25 \\
\hline \multirow[t]{3}{*}{$\begin{array}{l}\text { Complex } \\
\text { (angle, } \\
350 \mathrm{~mm} \text { ) }\end{array}$} & \multicolumn{3}{|c|}{$\ell / D$} & \\
\hline & straight & $0.75,0.5,0.25$ & 0.5 & 0.25 \\
\hline & elbow & $0.25,0.5$ & $0.25,0.5$ & $0.125,0.25$ \\
\hline
\end{tabular}




\subsection{1/qirt.2016.058}

\section{Experiment Methods}

Three types of pipes with processed defects were cooled using a cooling device. At this time, in order to prevent light from reflecting, radiation paint (KRYLON 4290 Ultra Flat Black) was applied to the object to keep its emissivity up to 0.97. Furthermore, temperature around the experiment system was kept constant at $25^{\circ} \mathrm{C}$ during the experiment. The IRT camera (FILR SC 5200) was used to measure the surface of the pipes and image data were obtained and analyzed from phases and amplitudes measured. The experiment was conducted at the pipe temperature set to $250^{\circ} \mathrm{C}$ or higher, under the condition derived for the purpose of this present, and with the distance of $1.5 \mathrm{~m}$ between the IRD camera and the cooling device. Specifications of the piping loop system and those of the cooling device are as follows:

\section{Experiment Methods}

Using cooling unit onto heated pipe, defect image can be obtained, and detailed experimental results for phase lock-in are listed in Table 4. Corresponding graph and image can confirm the defect. Overall image and lock-in IR image profile according to defect condition can confirm the temperature distribution as shown in Table 5. By differentiation of temperature profile, results of Table 7 can be obtained. Meanwhile, distance between defect is assumed to be distance between two inflections. From whole data in Table 5, the closest data are extracted to Table 6 , and those data are differentiated to extract the final results. On Table 6, results out of different defect depth and lengths are shown, and Table 11 are the results out of differentiation. On Table 8 , temperature distribution and wall thinning is shown according to different defect length. Table 9 shows the results for change in wall thinning depth and temperature distribution according to defect length using lock-in IR thermography. From these results, conventional IR thermography shows $15.54 \%$ of error, but $5.31 \%$ of error is reported in lock-in IR thermography. In addition, image collected from lock-in IR thermography is more vivid than the one from conventional IR image. By summarizing all these results, change in defect length and wall thinning depth can be identified with lock-in IR thermography.

Table 4. Thermography and lock-in thermography image

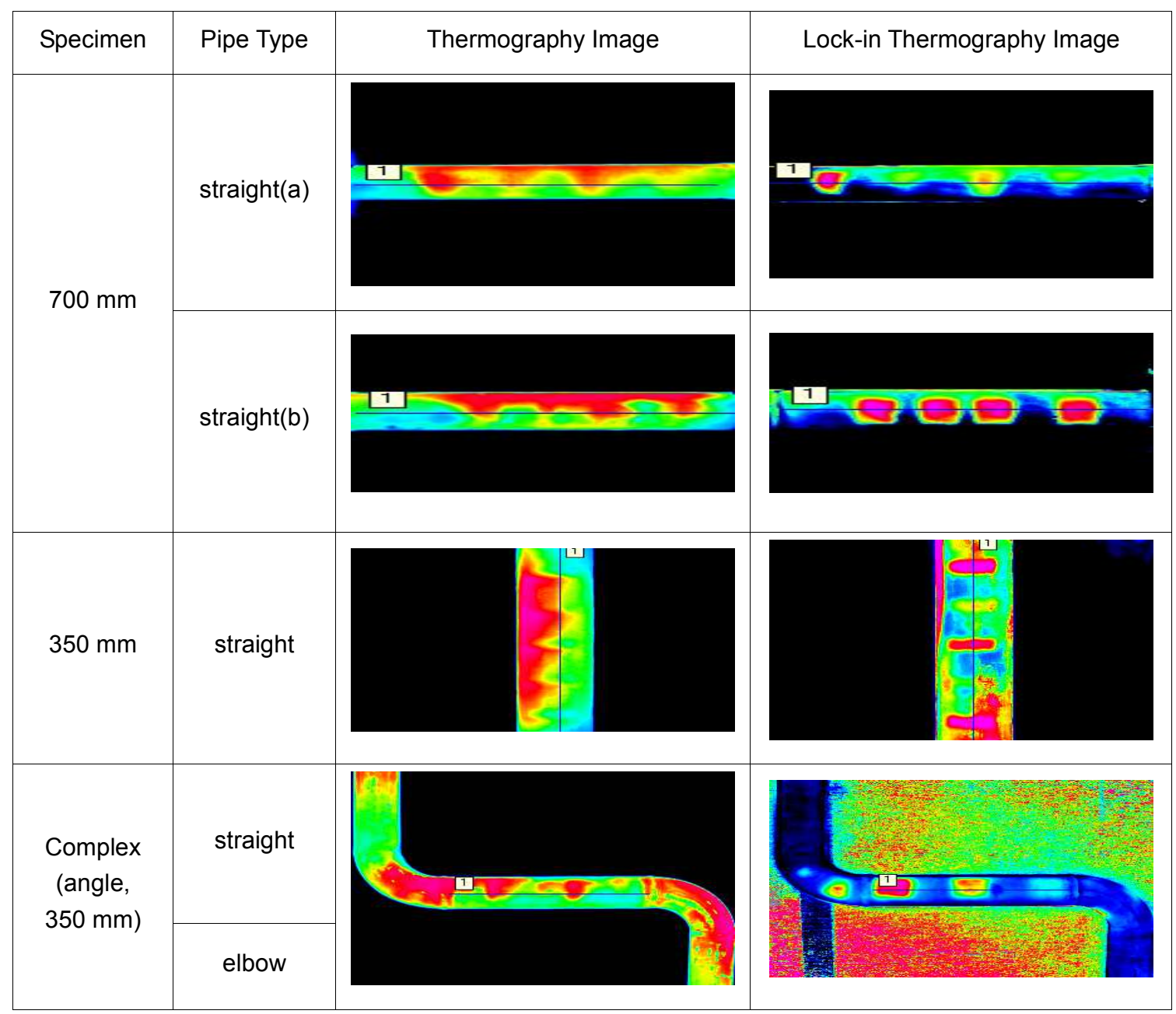


Table 5. Thermography and lock-in thermography temperature graph

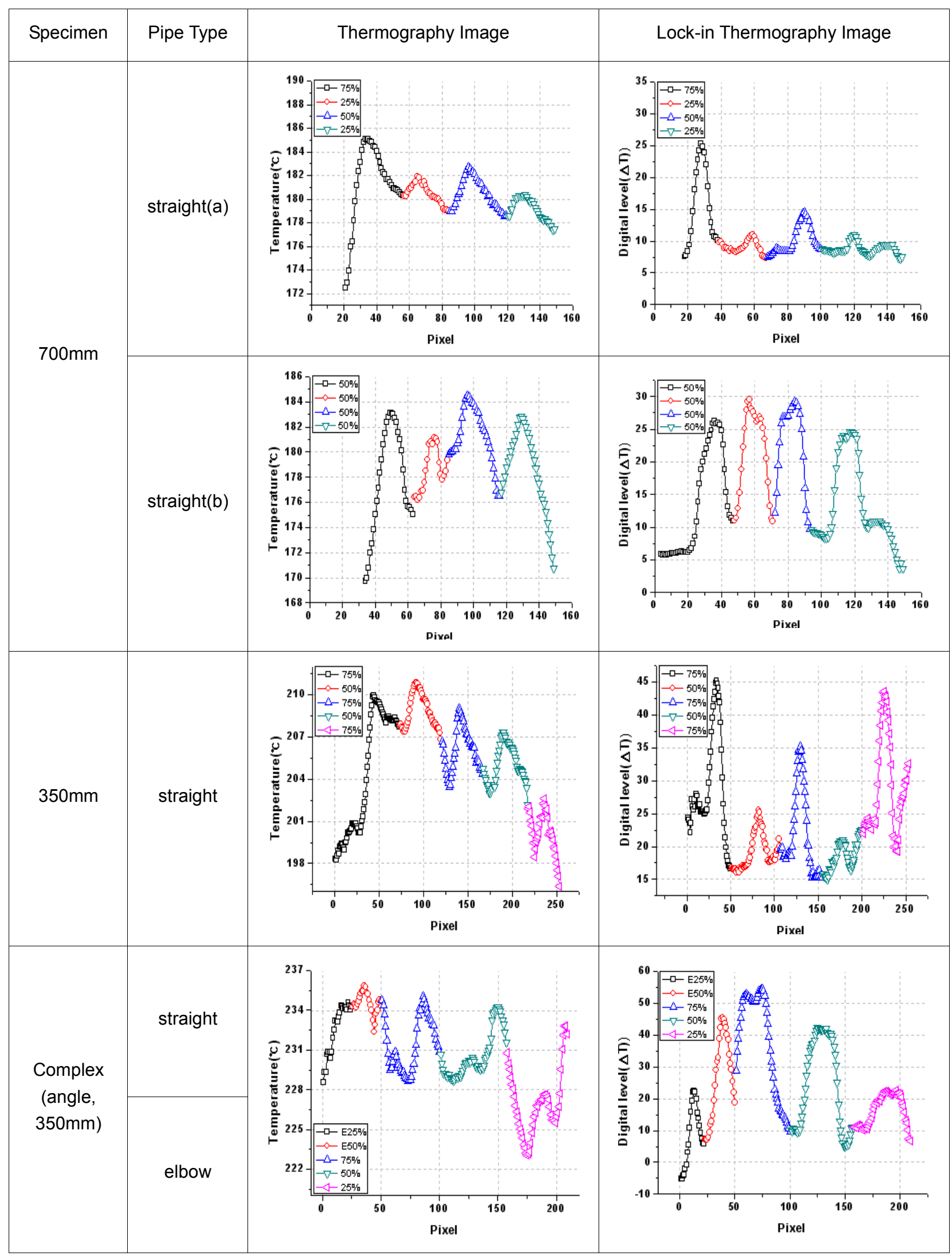


Table 6. Thermography and lock-in thermography temperature depth graph

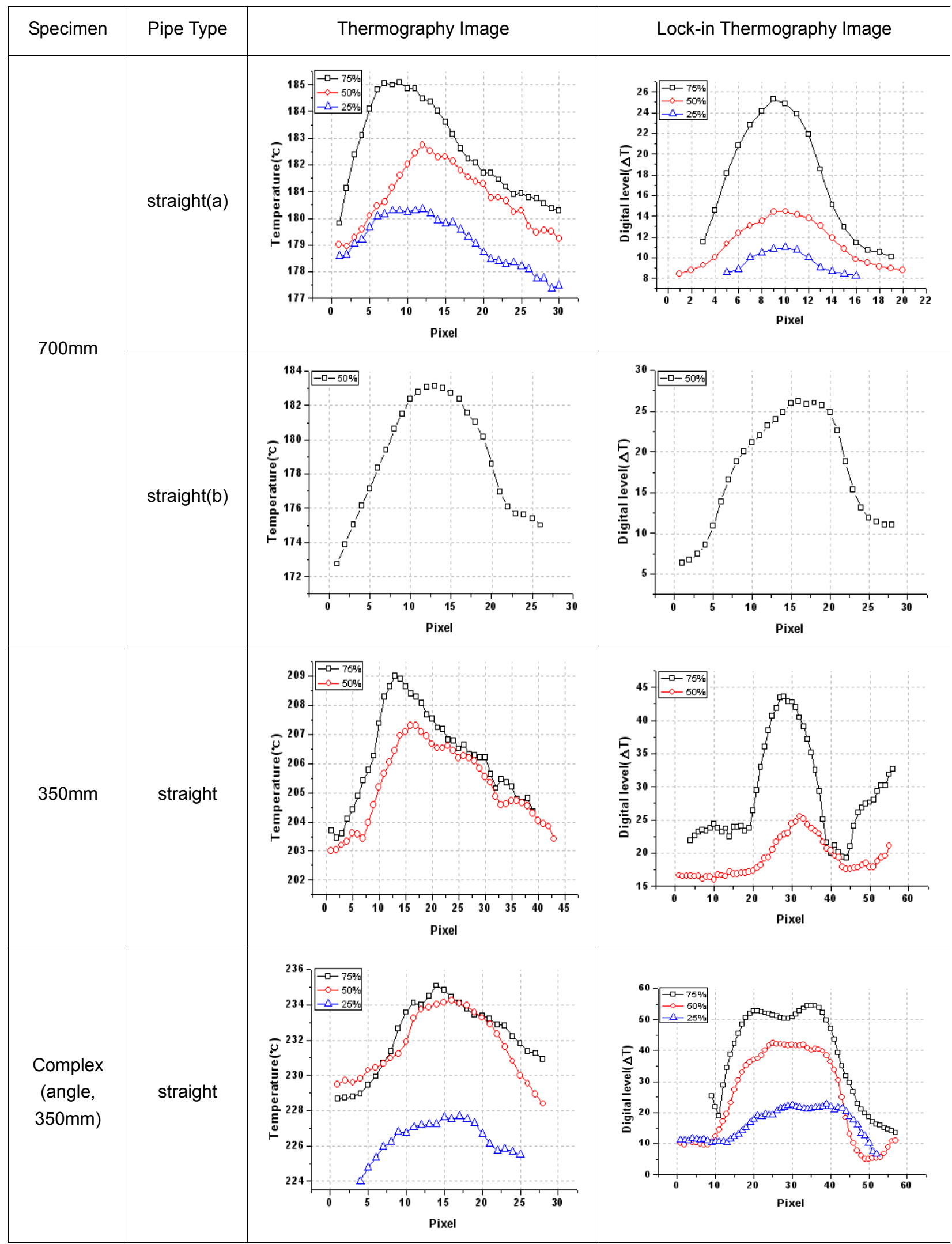


Table 7. Thermography and lock-in thermography differential graph

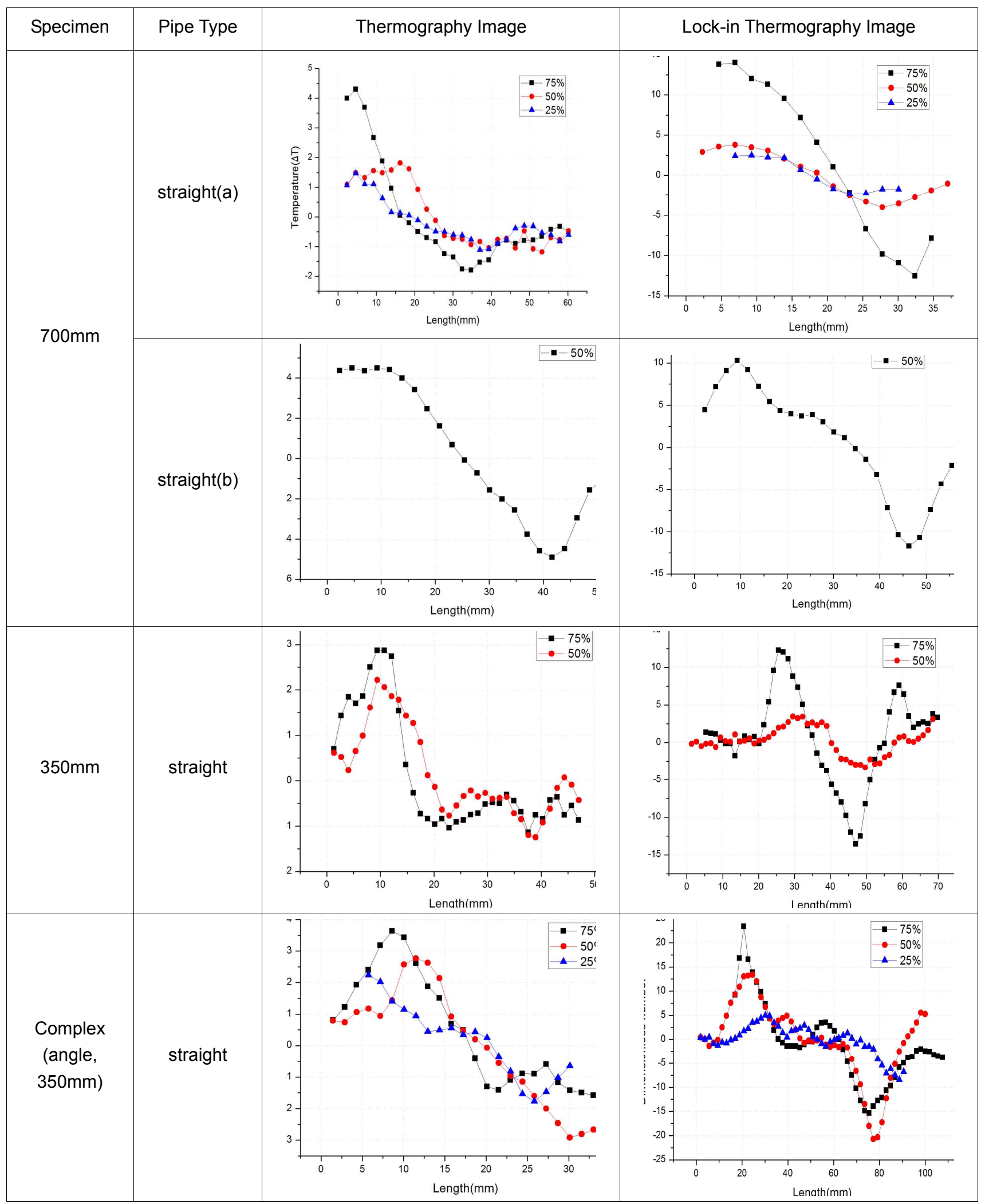


Table 8. Lock-in thermography defect length $(\mathrm{mm})$

\begin{tabular}{|c|c|c|c|c|}
\hline Specimen & Pipe Type & $\begin{array}{c}\text { Thinning } \\
\text { Depth }\end{array}$ & $\begin{array}{l}\text { Defect } \\
\text { length }\end{array}$ & $\begin{array}{l}\text { Measuing } \\
\text { efficiency }\end{array}$ \\
\hline \multirow{4}{*}{$700 \mathrm{~mm}$} & \multirow{3}{*}{ straight(a) } & $75 \%$ & 29.52 & $3.58 \%$ \\
\hline & & $50 \%$ & 26.84 & $5.82 \%$ \\
\hline & & $25 \%$ & 25.58 & $10.25 \%$ \\
\hline & straight(b) & $50 \%$ & 53.05 & $6.11 \%$ \\
\hline \multirow{2}{*}{$350 \mathrm{~mm}$} & \multirow{2}{*}{ straight } & $75 \%$ & 27.16 & $4.70 \%$ \\
\hline & & $50 \%$ & 26.56 & $6.81 \%$ \\
\hline \multirow{3}{*}{$\begin{array}{l}\text { Complex } \\
\text { (angle, } \\
350 \mathrm{~mm} \text { ) }\end{array}$} & \multirow{3}{*}{ straight } & $75 \%$ & 54.72 & $3.15 \%$ \\
\hline & & $50 \%$ & 54.52 & $3.50 \%$ \\
\hline & & $25 \%$ & 58.69 & $3.88 \%$ \\
\hline \multicolumn{4}{|c|}{ Average(\%) } & $5.31 \%$ \\
\hline
\end{tabular}

Table 9. Thermography defect length $(\mathrm{mm})$

\begin{tabular}{|c|c|c|c|c|}
\hline Specimen & Pipe Type & $\begin{array}{l}\text { Thinning } \\
\text { Depth }\end{array}$ & $\begin{array}{l}\text { Defect } \\
\text { length }\end{array}$ & $\begin{array}{l}\text { Measuing } \\
\text { efficiency }\end{array}$ \\
\hline \multirow{4}{*}{$700 \mathrm{~mm}$} & \multirow{3}{*}{ straight(a) } & $75 \%$ & 30.10 & $5.61 \%$ \\
\hline & & $50 \%$ & 23.15 & $18.77 \%$ \\
\hline & & $25 \%$ & 32.42 & $13.75 \%$ \\
\hline & straight(b) & $50 \%$ & 45.42 & $19.61 \%$ \\
\hline \multirow{2}{*}{$350 \mathrm{~mm}$} & \multirow{2}{*}{ straight } & $75 \%$ & 23.44 & $17.75 \%$ \\
\hline & & $50 \%$ & 23.44 & $17.75 \%$ \\
\hline \multirow{3}{*}{$\begin{array}{c}\text { Complex } \\
\text { (angle, } \\
350 \mathrm{~mm} \text { ) }\end{array}$} & \multirow{3}{*}{ straight } & $75 \%$ & 48.40 & $14.34 \%$ \\
\hline & & $50 \%$ & 48.66 & $13.88 \%$ \\
\hline & & $25 \%$ & 46.10 & $13.41 \%$ \\
\hline \multicolumn{4}{|c|}{ Average(\%) } & $15.54 \%$ \\
\hline
\end{tabular}

\section{Conclusion}

In this study, the following conclusions were obtained:

1) At $1.5 \mathrm{~m}$ of measurement distance for different defect length and wall thinning depth, conventional IR image has $15.54 \%$ of error, meanwhile, lock-in IR thermography reported $5.31 \%$.

2) Lock-in IR thermography is more precise when depth of defect is deeper, which is contradictory for conventional IR thermography.

3) Results from this study can be used as fundamental background for confirming the location of defect using cooling unit. 


\section{REFERENCES}

[1] Y. M. Cheong, "Experimental evidence and analysis of a mode conversion of guided wave using magnetostrictive strip transducer," Journal of the Korean Society for Nondestructive Testing, Vol. 29, No. 2, pp. 93-97 (2009)

[2] M. Y. Choi and W. T Kim, "The utilization of nondestructive testing and defects diagnosis using infrared thermography," Journal of the Korean Society for Nondestructive Testing, Vol. 24, No. 5, pp. 525-531 (2004)

[3] Korea Hydro \& Nuclear Power Co., "Manage- ment program for thinned pipe in NPP secondary system," Final Report-00NJ12 (2003)

[4] S. H. Lee, T. R. Kim, S. C. Jeon and K. M. Hwang, "Thinned pipe management program of Korean NPPs," Transaction of SMiRT-17, Paper \#O04-2, Prague, Czech Repblic (2003)

[5] IAEA, "Development of protocols for corrosion and deposits evaluation in pipes by radiography," IAEA-TECDOC$1445(2005)$

[6] T. Knook, M. Persoz, S. Trevin, S. Friol, M. Moutrille and L. Dejoux, "Pipe wall thinning management at Electricite de France (EDF)," E-Journal of the Advanced Maintenance, Vol. 2, pp. 1-13 (2010)

[7] K. J. Lee, H. S. Jang, H. C. Jung and K. S. Kim, "Quantitative out-of-plane deformation measurement of pressure vessel with the defect using shearography," Journal of the Korean Society for Precision Engineering, Vol. 23, No. 10 , pp. 36-42 (2006)

[8] X. P. V. Maldague, "Trends in Optical Nondestructive Testing and Inspection," P. K. Rastogi, Elsevier Science, Switzerland (2000)

[9] O. Breitenstein and M. Langenkamp, "Lock-in Thermogarphy," Springer, Germany, pp. 1-38, (2003)

[10] J. H. Park, M. Y. Choi and W. T. Kim, "Shearing phase lock-in infrared thermography for defects evaluation of metallic specimen," Journal of the Korean Society for Nondestructive Testing, Vol. 30, No. 2, pp. 91-97, (2010) 